\title{
PATTERNS OF CHRONIC KIDNEY DISEASE - MINERAL BONE DISEASE AND ITS RELATIONSHIP WITH SOCIO-DEMOGRAPHIC FACTORS AMONG THE PATIENTS OF CHRONIC KIDNEY DISEASE UNDERGOING HEMODIALYSIS
}

\author{
Batool Butt, Taymmia Ejaz, Sohail Sabir*, Ghayas Khan* \\ Pak Emirates Military Hospital/National University of Medical Sciences (NUMS) Rawalpindi Pakistan, *Armed Forces Institute of \\ Urology/National University of Medical Sciences (NUMS) Rawalpindi Pakistan
}

\begin{abstract}
Objective: To determine the prevalence of patterns of CKD-MBD in dialysis patients at a tertiary care hospital and analyze its relationship with various socio demographic factors.

Study Design: Analytical cross sectional study.

Place and Duration of Study: Pak Emirates Military Hospital Rawalpindi, from Jul 2017 to Dec 2017.

Methodology: The sample population comprised of 100 patients undergoing hemodialysis and blood samples of calcium, phosphate, alkaline phosphatase and intact PTH were obtained from these patients. CKD-MBD was classified on the basis of biochemical abnormalities and their relationship with age, gender, marital status, smoking history, dialysis count per week, dialysis duration was assessed.

Results: Out of 82 patients consisting of 62 males and 20 females, the mean age was $49.8 \pm 16$ years, $68 \%$ of dialysis patients had biochemical abnormalities of which $73 \%$ showing high turn over bone disease and $26.8 \%$ showing low turnover bone disease (adynamic and osteomalacia). After applying the logistic regression we found that age, gender, dialysis vintage and other socio-demograhic factors had no significant association with the CKD-MBD subtypes.

Conclusion: Biochemical abnormalities although common in dialysis patients but the sturdy interconnection between them is still shrouded in disputation. Special consideration should be remunerated to the dialysis population with different spectrum of CKD-MBD as propitious management can procrastinate the progression of CKD and eventually paring down the cardiovascular morbidity and mortality.
\end{abstract}

Keywords: CKD-MBD, CKD, Hemodialysis.

This is an Open Access article distributed under the terms of the Creative Commons Attribution License (http://creativecommons.org/licenses/by/4.0), which permits unrestricted use, distribution, and reproduction in any medium, provided the original work is properly cited.

\section{INTRODUCTION}

Chronic kidney disease the tip of an iceberg of covert disease, with a prevalence of about $14 \%$ in US population ${ }^{1,2}$ has always been a major public issue with increased health-care expenditures which not only pose great burden on a developing urbanising country like Pakistan with a struggling frugality but also affects productivity of nation ${ }^{3}$. CKD-MBD, previously called renal osteodystrophy, one of the non-traditional risk factor for cardiovascular morbidity and mortality refers to broad spectrum of disorders with abnormal mineral metabolism, begins when GFR falls below $60 \mathrm{ml} / \mathrm{min}$ and evident as high turn over

Correspondence: Dr Batool Butt, Resident Neurologist, College of Physician and Surgeon Pakistan, Islamabad Pakistan

Received: 31 Jan 2019; revised received: 14 Feb 2019; accepted: 15 Feb 2019 (secondary hyperparathyroidism) or low turn over bone disease (adynamic bone disease or osteomalacia). In 2017, KDIGO an nonpartisan and unremunerative foundation, recommended guidelines for CKD-MBD management with specific target ranges for calcium phosphorus and i.PTH ${ }^{4}$.

Recent experimental and epidemiological data have refuelled the long standing debate of CKD-MBD putative reltaionship with hypertension, cardiovascular events and renal disease progression $^{5}$. There is dearth of representative data on the prevalence of CKD-MBD and its spectrum because of the differences among different ethnicities and dialysis modality. The relative prevalence of each of these types varies in different communities and with different dialysis modalities. Low turn over bone disease osteomalacia and mixed uremicosteodystrophy were more 
prevalent in Brazil, Uruguay, and Argentina while Portuugal and Spain had the hyperparathyroid bone - Osteitisfibroscystica was also the frequent histological diagnosis on bone biopsies as reported by Onyemekehia.

The rationale of this study is to determine prevalence of CKD-MBD and its relationship with socio-demographic factors in dialysis populace at tertiary care hospital as no such studies have so far been conducted in our population before, and also to channel more efforts to help dialysis patients in achieving KDIGO targets for calcium, phosphorus and i.PTH, leading to delay in progression of CKD and also curtailing the cardiovascular mortality thus reducing the robust financial burden in these patients especially in developing countries like Pakistan where people can't bear the burden of renal replacement therapy. This fact highlights the need to size up its burden accurately first and then make endeavours in implementing more relevant strategies to correct abnormalities in mineral metabolism so as to arrest the progression of CKD.

\section{METHODOLOGY}

This cross sectional study was conducted at a dialysis unit of Pak Emirates Military Hospital Rawalpindi between Jul 2017 to Dec 2017. All patients being hemodialysed for atleast 03 months and with up-to-date biochemical explorations being included. Exclusion criteria were the patients $<18$ years of age or those who did not consent to or those with a past history of orthopedic or skeletal abnormalities not related to recent ailment, Patients who were pregnant or were undergoing dialysis due to reason other than CKD were excluded.

Subjects were provided with a detailed description of the study and were inducted into the study after written informed consent. Sociodemographic variables including age, gender and education and marital status, BMI, duration of dialysis and dialysis count per week and history of smoking of patients were obtained. The cause of CKD and detailed history regarding the intake of phosphate binders (calcium vs non- calcium based) and vitamin D analogues, symptoms like pruritis, bone pain or fractures was established for each patient. About $10 \mathrm{ml}$ of venous blood was obtained from patients to perform biochemical tests which included serum calcium, phosphate, alkaline phosphatase, intact PTH and vitamin D. Bone biopsy was not done because of refusal by many patients Biochemical markers were studied according to the internationally accepted ranges. The socio demographic data of the full sample of subjects participating in the research was entered in a structured performa.

According to KDIGO 2017 - CKD-MBD is a systemic disorder of mineral and bone metabolism in Chronic kidney disease patients with abnormalities of calcium, phosphorus, PTH, or vitamin $\mathrm{D}$ metabolism, or abnormalities of bone turnover, mineralization, volume, linear growth, orstrength, or vascular or soft tissue calcification ${ }^{4}$ Normal values for calcium $-8.5-10.5 \mathrm{mg} / \mathrm{dl}$, Phosphate-2.5-4.5g/dl, Alkaline phosphatase 54-260 $\mathrm{IU} / \mathrm{L}$, Intact PTH $10-65 \mathrm{pg} / \mathrm{ml}$. In the absence of bone histology, High turn over bone diseasei.PTH levels $>450 \mathrm{pg} / \mathrm{ml}$, hyperphosphatemia and variable calcium levels and low turn over bone disease-(osteomalacia and adynamic bone disease) i.PTH $<100 \mathrm{pg} / \mathrm{ml}$ but with low limit of normal cacium, phosphate and alkaline phosphatase level-osteomalacia further differentiated from adynamic bone disease on the basis of typical looser zones on xrays.

Socio-demographic characteristics of participants were described by using the descriptive statistics. Continuous variables were presented as means and standard deviation while discrete variables as frequency and percentages. Chi-square was used to determine between-group variances in categorical correlates. Binary logistic regression analysis was done to evaluate factors correlation with CKD-MBD. All statistical analysis was performed using Statistics Package for Social Sciences version 20.0. Chi-square test was used and differences between groups were considered significant if $p$-values were less than 0.05. 


\section{RESULTS}

A total of 100 patients of CKD undergoing dialysis were approached to participate in the study. Fifteen refused participation and 02 were ineligible due to the exclusion criteria and 01 died because of myocardial infarction leaving 82 patients consisting of 62 males and 20 females. The mean age was $49.8 \pm 16$ years. The common etiologies of CKD in this study were hypertensive nephropathy $(40 \%)$, followed by diabetic/ hypertensive nephropathy (25\%), chronic glomerulonephritis (12\%), APKD (5\%) etiology unknown $(10 \%)$. The mean BMI was $23.8 \pm 3.9 \mathrm{~kg} / \mathrm{m}^{2}$ with majority of patients having BMI between 18.5$24.5 \mathrm{~kg} / \mathrm{m}^{2}$. All patients were dialysed with cal-

Table: Clinical and biological parameters of CKDMBD in dialysis patients.

\begin{tabular}{l|c|c}
\hline & $\begin{array}{c}\text { High Turn } \\
\text { Over Bone } \\
\text { Disease }\end{array}$ & $\begin{array}{c}\text { Low Turn } \\
\text { Over Bone } \\
\text { Disease }\end{array}$ \\
\hline Age (y) & $48.2 \pm 29$ & $51 \pm 40$ \\
\hline Sex ratio & 2.75 & 0.22 \\
\hline Weekly Kt/V & 1.3 & 1.6 \\
\hline Clinical Symptoms (No. of cases) \\
\hline Bone pain & 20 & 17 \\
Pruritis & 02 & 05 \\
Fractures & 32 & 19 \\
\hline Biological Parameters & $9.1 \pm 5$ & $8.0 \pm 5$ \\
\hline Calcium (mg/dl) & $4.0 \pm 2$ & $3.2 \pm 2$ \\
Phosphate (mg/dl) & $90.8 \pm 18.2$ & $30.5 \pm 11$ \\
Ca*P product & $280 \pm 120$ & $105 \pm 70$ \\
Alkaline Phospha- & $95 \pm 14$ & $5.0 \pm 2$ \\
te (IU/L) & $9.0 \pm 7.5$ & $7.0 \pm 2.5$ \\
i.PTH (pg/ml) &
\end{tabular}

cium dialysate solution $1.25 \mathrm{mmol} / \mathrm{l}$, had an adequate $\mathrm{Kt} / \mathrm{V}>1.2$, and all patients with high turn over bone disease were taking phosphate binders and vitamin $\mathrm{D}$ analogues. The prevalence of mineral bone biochemical abnormalities in the dialysis subjects was $68 \%$, with $60(73 \%)$ patients showing high turn over bone disease (secondary hyper-parathyroidism) and $22(26.8 \%)$ patients showing low turn over bone disease (adynamic and osteomalacia) Clinical and biochemical characteristics are shown in table. Age, dialysis vintage, gender education status did not find any association with CKD-MBD when regression analysis was done.

\section{DISCUSSION}

Our study population had a high prevalence of mineral bone biochemical abnormalities (68\%) which is in accordance with various international studies in both developed and developing countries. In a similar study in neighbor India, mineral bone abnormalities were found in $74 \%$ of study population with $40 \%$ and $34 \%$ having high turn over and adynamic bone disease respectively 6 , $58 \%$ had high turn over and $18 \%$ were at risk for low turn over disease in another study in India by Vikrant et al7. These findings are in agreement with our study. $75 \%$ had MBD in a study by Sanusi et al in Nigeria 8,73.4\% in a South African study ${ }^{9}$; with over half of the study population having high turn over bone disease. Some $66.9 \%$ had mineral abnormalities in a study ${ }^{10}$ by Seck et al in Senegal, among them $72 \%$ had high turn over and $26 \%$ had adynamic bone disease.

Hyperparathyroidism was seen in $73.4 \%$ of study population in South Africa 9,50\% in a Chinese study ${ }^{11}$ which is considerably higher than $31 \%$ observed in DOPPS study $1282.7 \%$ has secondary hyperparathyroidism in Indian population undergoing HD, 40.6\% had iPTH levels $>400$ $\mathrm{pg} / \mathrm{ml}$ in the study ${ }^{7}$. Some $22 \%$ of Gulf Cooperation Council Countries (GCC) DOPPS study population had iPTH levels $>600 \mathrm{pg} / \mathrm{ml} 13$ and $27.1 \%$ of study population in Brazil had iPTH $>600 \mathrm{pg} /$ $\mathrm{ml}^{13}$ which is in sharp contrast to $11 \%$ having iPTH $>600 \mathrm{pg} / \mathrm{ml}$ in DOPPS (phase4) ${ }^{12}$ study in America and Europe. These differences can be explained by dietary practices, racial variations, adherence to medication, access to HD, HD frequency and prescription. Racial differences have been noted in various studies particularly in relation to dietary practices, vitamin D levels, increased hyperparathyroidism in African Americans as ethnic differences exist in skeletal responsiveness to $\mathrm{PTH}^{14}$ Although Pakistan is an ethnically diverse country our study did not explore the racial differences in mineral bone abnormalities. 
High serum phosphorus levels $>6 \mathrm{mg} / \mathrm{ml}$ were observed in average $26 \%$ of GCC $1378.1 \%$ had hyper phosphatemia $>4.5 \mathrm{mg} / \mathrm{ml}$ in an Indian study by Vikrant et $a l^{7}, 30 \%$ were above range in a study by Kulkarni et al $1535.8 \%$ of Brazilian study population ${ }^{13}$ some $57 \%$ in South African study ${ }^{9}$ and $75 \%$ in Nigerian study population ${ }^{8}$ also had hyperphosphatemia. Variations in serum phosphate levels and high prevalence can be explained due to conventical hemodialysis as compared to nocturnal HD and dietary practices/ phosphate binder use ${ }^{9}$.

Most common clinical feature in our study was pruritis reported by $45 \%$, it was also the most commonly reported symptom ${ }^{10}$ in a study by Seck et al, however bone pain was most reported in study by Bansel et al6 bone fractures were more commonly seen in adynamic bone disease in our population. Only 5\% of study complained of bone pain in a Nigeran study ${ }^{8}$.

Hypertension was the common cause of ESRD in our study, in concordance with other studies $8,13,14$, however Diabetes was the leading cause in other various studies,7. It is stipulated that Mineral bone disorders are more common in diabetics due to low vitamin D levels, caused by proteinuria resulting in urinary loss of vitamin-d binding proteins, decreased osteoblast life span and accumulation of advanced glycated end products ${ }^{9,13}$. Adynamic bone disease was more common in diabetics in various studies ${ }^{13}$. Diabetic patients also had higher prevalence of $\mathrm{iPTH}$ levels $<150 \mathrm{pg} / \mathrm{ml}$ in one study ${ }^{13}$ Prevalence of high iPTH $>600 \mathrm{pg} / \mathrm{ml}$ was two-fold higher in non diabetics in one study (32\% vs $12 \%$ ) 13 high serum phosphorus levels $>5 \mathrm{mg} / \mathrm{ml}$ was also more common in non diabetics. Age and diabetes were also found to be risk factor for adynamic bone disease in one study ${ }^{7}$.

Although there was no significant association found between age and MBD in our study, studies have found lower phosphorous levels in elderly population ${ }^{16}$, younger patients had 3 -fold higher odds of having high phosphorus levels $>6 \mathrm{mg} / \mathrm{ml}$ in one study while other were in agr- eement with our study in finding no association of mineral abnormalities with increasing age ${ }^{9,17}$. iPTH levels were also seen to decrease with increasing age in various studies ${ }^{13}$. Elderly have lower bone turnover, low intake low physical activity and low compliance with medications resulting in mostly low bone turn over diseases ${ }^{13}$ which can explain these variations in different studies.

One study found a significant positive association of iPTH levels with dialysis duration (mean 85.9 month) ${ }^{13}$, however we did not find any such association in our study.

With regards to education status, studies have shown adherence to medication and dietary modifications were more likely to occur in population with more awareness, $48 \%$ were unaware of foods rich in phosphorous and only $8 \%$ had knowledge of phosphate binders in one study ${ }^{18}$ which highlights the role of information and education in CKD patients, however no such association was found in our study and in another study exploring this difference ${ }^{13}$.

There was increase prevalence of MBD in minority incident population in a U.S based study, poor socio-economic status, poverty and lack of health insurance was cited as common factors ${ }^{17}$. However it is to be noted that majority of study population in our study were individuals who had cost-free access to hemodialysis and medications although access to high cost phosphate binders such as sevelamer was less, the prevalence of MBD may be higher in study population not having these facilities in Pakistan.

Our study has several limitations. This was a cross-sectional study hence causal relationship cannot be established with any associated factors. Bone biopsy is considered the gold standard for diagnosing MBD which was not carried out due to its invasive nature and cost. The iPTH assays were not standardized. The study also didn't not take into account dietary factors and habits, the use of and/ compliance/with vitamin D analogues and phosphate binders. It was a, single center study with a small study population hence 
results may not be generalized on overall population. However despite these limitations this stu$\mathrm{dy}$ is one of the first to investigate the prevalence of CKD-MBD and associated sociodemographic factors in Pakistan, considering limited data on the topic we recommend a National or Regional Data registry of patients undergoing hemodialysis.

\section{CONCLUSION}

Biochemical abnormalities although common in dialysis patients but the but the sturdy interconnection between them is still shrouded in disputation. Special consideration should be remunerated to the dialysis population with different spectrum of CKD-MBD as propitious management can procrastinate the progression of CKD and eventually paring down the cardio-vascular morbidity and mortality.

\section{CONFLICT OF INTEREST}

There is no conflict of interest to be declared by any author.

\section{REFERENCES}

1. Saran R, Li Y, Robinson B, Abbott KC, Agodoa LY, Ayanian J, et al. US renal data system 2015 annual data report: epidemiology of kidney disease in the United States. Am J Kidney Dis 2016; 67(1): 305.

2. Imran S, Shiekh A, Saeed Z, Khan SA, Malik AO, Patel J, et al. Burden of chronic kidney disease in an urban city of Pakistan, a cross-sectional study. J Pak Med Assoc 2015; 65(4): 366-69.

3. Jafar TH, Haaland BA, Rahman A, Razzak JA, Bilger M, Naghavi $M$, et al. Non-communicable diseases and injuries in Pakistan: strategic priorities. Lancet 2013; 381 (9885): 2281-90.

4. Chapter 1: Introduction and definition of CKD-MBD and the development of the guideline statements. Kidney Int 2009; 76113: S3.

5. Herzog CA, Asinger RW, Berger AK, Charytan DM, Diez J, Hart RG, et al. Cardiovascular disease in chronic kidney disease. A clinical update from kidney disease: Improving global outcomes. Kidney Int 2011; 80(6): 572-86.
6. Bansal B, Gahlot S, Agrawal DK. Clinical pattern of bone mineral derangements, if any (High bone turnover disease/Low bone turnover disease) in CKD Patients undergoing Haemodialysis. 2016; 4(12): 1101-08.

7. Vikrant S, Parashar A. Prevalence and severity of disordered mineral metabolism in patients with chronic kidney disease: A study from a tertiary care hospital in India. Indian J Endocrinol Metab 2016; 20(4): 460-67.

8. Sanusi A, Arogundade F, Oladigbo M, Ogini L, Akinsola A. Prevalence and pattern of renal bone disease in end stage renal disease patients in ile-ife, Nigeria. West Afr J Med 2011; 29(2): 75-80.

9. Waziri B, Duarte R, Naicker S. Biochemical markers of mineral bone disorder in South African patients on maintenance haemodialysis. Afr Health Sci 2017; 17(2): 445-52.

10. Seck SM, Dahaba M, Ka EF, Cisse MM, Gueye S, Lemrabott AO. Mineral and bone disease in black african hemodialysis patients: a report from senegal. Nephrourol Mon 2012; 4(4): 613-16.

11. Sun YP, Yang WJ, Li SH, Han YY, Liu J. Clinical epidemiology of mineral bone disorder markers in prevalent hemodialysis patients in the Xinjiang uyghur autonomous region in China. Biomed Res Int 2017; 2017(1): 4-8.

12. Tentori F, Wang M, Bieber BA, Karaboyas A, Li Y, Jacobson SH, et al. Recent changes in therapeutic approaches and association with outcomes among patients with secondary hyperparathyroidism on chronic hemodialysis: The DOPPS study. Clin J Am Soc Nephrol 2015; 10(1): 98-109.

13. Abrita RR, Pereira BS, Fernandes NS, Abrita R, Huaira RMNH, Bastos MG, et al. Evaluation of prevalence, biochemical profile, and drugs associated with chronic kidney disease-mineral and bone disorder in 11 dialysis centers. Braz J Nephrol 2018; 40(1): 26-34.

14. Waziri B, Duarte R, Dickens C, Peek TD, George J, Rekhviashvili $\mathrm{V}$, et al. Racial variations in the markers of mineral bone disorders in CKD patients in South Africa. Kidney Int Rep 2018; 3(3): 583-91.

15. Kulkarni MJ, Jamale T, Hase NK, Jagdish PK, Kesker V, Patil H, et al. Kidney diseases and transplantation renal data from asiaafrica a cross-sectional study of dialysis practice-patterns in patients with chronic kidney disease on maintenance hemodialysis. Saudi J Kidney Dis Transpl 2015; 26(5): 1050-56.

16. Pelletier S, Roth H, Bouchet JL, Drueke T, London G, Fouque D. Mineral and bone disease pattern in elderly haemodialysis patients. Nephrol Dial Transplant 2010; 25(9): 3062-70.

17. Goel N, Pokharna H, Torres W, Gnanasekaran I. Mineral metabolism status of incident ESRD patients in an inner city hemodialysis unit. Am J Kidney Dis 2009; 53(4): A39.

18. Chen Y, Li Z, Liang X, Zhang M, Zhang Y, Xu L, et al. Effect of individual health education on hyperphosphatemia in the Hakkas residential area. Ren Fail 2015; 37(8): 1303-07. 